\title{
Development of a Duplex Real-time PCR for Differentiation of Salmonella Typhimurium and Monophasic Serovars
}

\author{
Amany Abd El -Lattief ${ }^{1}$, Sherif Marouf ${ }^{2}$, Amany El - Bialy ${ }^{1}$ and Jakeen El - Jakee ${ }^{2 *}$ \\ ${ }^{I}$ Animal Health Research Institute, Doki, Giza, Egypt \\ ${ }^{2}$ Microbiology Department, Faculty of Veterinary Medicine, Cairo University, Egypt \\ *Corresponding author's E-mail jeljakee@ yahoo.com; ORCID: 0000-0002-5299-3783
}

Received: 26 Feb. 2020

Accepted: 05 Apr. 2020

\begin{abstract}
Salmonella Typhimurium is the most Salmonella serovar causing acute gastroenteritis and diarrhea. Serovar 1, 4, [5], 12: i:- is considered a monophasic variant of $S$. Typhimurium that threaten public health. Fifty-eight serologically confirmed Salmonella strains were investigated by PCR using $16 S \mathrm{rRNA}$ and fliC genes. All 58 strains harbored $16 \mathrm{~S}$ $r R N A$ while 21 strains harbored fliC gene that included $S$. Typhimurium (12), S. Kentucky (6), Salmonella variant strain serotype 1, 4, [5],12:i:- (1), S. Lagos (1), and S. Kedougou (1). A duplex TaqMan real-time PCR was performed for differentiating between biphasic $S$. Typhimurium and monophasic serovar 1, 4, [5], 12:i:- using fljB1, 2 and $f l i B / I S 200$ in the $f l i A-f l i B$ intergenic region. Ten out of twelve $S$. Typhimurium harbored $f l j B 1$, 2, while Salmonella variant strain serotype 1, 4, [5], 12:i:- lacked this gene. Thirteen strains (12 S. Typhimurium and the variant strain serotype 1, 4, [5], 12:i:-) were positive for fliB/IS200 that is a specific gene for $S$. Typhimurium (biphasic and monophasic ). The result of duplex TaqMan real-time PCR indicated that $10 \mathrm{~S}$. Typhimurium strains were biphasic while two $S$. Typhimurium strains and the variant strain serotype 1, 4, [5], 12:i:- lack $f l j B 1,2$ and had fliB/IS200 were monophasic S. Typhimurium. It is noticed that prolonged subculture and repeat phase inversion method leads to the formation of flakes that in turn cause wrongly serotype identification, therefore, real-time PCR is rapid and can be used for identifying and differentiating between biphasic and monophasic $S$. Typhimurium.
\end{abstract}

Key words: Biphasic and monophasic $S$. Typhimurium, flj gene, Real-time PCR, Salmonella.

\section{INTRODUCTION}

Salmonella enterica is zoonotic bacteria transmitted through the food chain and is an important cause of disease in humans (Osman et al., 2014a; Shaw et al., 2018). It is the second leading cause of bacterial foodborne illness (Foley et al., 2008; Persad and LeJeune, 2018). The genus Salmonella has a large number of serotypes that differ in pathogenicity and host specificity. Despite the widespread use of serotyping, it has deficiencies that limit its utility, including that it often takes three or more days to give a result and approximately $5-8 \%$ of isolates are partially typed.

In addition, prolonged subculture can affect the antigenic properties of strains. Highly trained laboratories are required to type strains accurately, also high costs of producing and validity specific antisera to rare antigens are problematic (Kim et al., 2006). Delay caused by identification can hinder the response to a disease outbreak and/ or epidemiological surveillance. Therefore, various studies have been explored alternative assays to differentiate Salmonella isolates, such as the search for genes that can be used as potential molecular substitutes for serotyping. However, the genes tested so far have often yielded inconsistent results (Osman et al., 2014b; Hua Zou et al., 2016). Real-time PCR for detection of Salmonella has been brought to inter-laboratory trial, the results of which support their use as international standard methods (Malorny et al., 2007).

Two genomic sites, 16S rRNA and fliC gene have been reported as candidates suitable for common and specific detection of Genus Salmonella, and $S$. Typhimurium, respectively by real-time PCR (Imre et al., 2005). The 16SrRNA can be used for the rapid and multiple detections of the 16 pathogenic bacteria frequently isolated from contaminated foods that are important for food safety (Shin et al., 2016). The $16 \mathrm{~S}$ ribosomal RNA (rRNA), approximately 1500 nucleotides in length of the prokaryotic ribosome, provides sufficient highly-conserved sequences to design the probes for developing microbial detection (Woo et al., 2003). The 
fliC gene codes for the Hi antigen of Salmonella targeting the fliC-i allele greatly increases the specificity for $S$. Typhimurium identification (Pathmanathan et al., 2003).

$S$. Typhimurium, according to the WhiteKaufmann-Le Minor serotyping scheme (Grimont and Weill, 2007), exhibits the antigenic formula 1,4 , [5], 12: $\mathrm{i}: 1,2$, where " $i$ " and " 1,2 " are the first and second flagellar antigens expressed by the bacterium at different times, hence the serotype description as biphasic (Soyer et al., 2009). Antigenic variants that lack either the first or second $\mathrm{H}$ antigens or both have been described. In recent years isolates with antigenic formula 1, 4, [5], 12:i:- have become increasingly important as a public health risk and more frequently recovered from humans and foodproducing animals (Hopkins et al., 2010). The European Food Safety Authority (EFSA, 2010) recently recommended the confirmation of the serological identification of monophasic $S .1$, 4, [5], 12:i:- strains using a polymerase chain reaction (PCR) protocol based on the detection of $f l j B$ gene and the fliA-B intergenic region. The $f l j B 1,2$ gene codes for second phase flagellar antigen present in $S$. Typhimurium. Indeed, all serovar Typhimurium strains and its monophasic/ nonmotile variants have an IS200 fragment of $1 \mathrm{~kb}$ in the fliA-B intergenic region, which is not detected in the other serovars. Within the flagellin gene cluster of Salmonella Typhimurium carries a conserved IS200 insertion sequence located downstream of the flagellin N-methylase gene $(f l i B)$ and upstream of the flagellar biosynthesis sigma factor gene (fliA), this element found in Salmonella Typhimurium and its variant (Burnens et al., 1997). Several studies have reported DNA sequences for Salmonella flagellin genes. As of June 2003, 74 complete or partial Salmonella fliC alleles and 25 complete or partial Salmonella $f l j B$ allele sequences had been documented in GenBank release no. 132, excluding complete genome sequences.

Thus, this study aimed, first, to confirm Salmonella strains using 16SrRNA gene and S. Typhimurium using fliC by Syber green-based real-time PCR, and second, to differentiate between $S$. Typhimurium and monophasic serovar 1, 4, [5], 12:i:- using fljB1,2 and IS200 in the fliA$f l i \mathrm{~B}$ region using TaqMan real-time PCR.

\section{MATERIALS AND METHODS}

\section{Strains}

A total of 58 Salmonellae isolates recovered from chicken in previous work (Abd El-Lattief, 2014), was identified serologically by slide agglutination test according to White-Kauffmann le minor scheme (Grimont and Weill, 2007) using SIFIN antisera, Berlin, kindly obtained from Serology Unit, Animal Health Research Institute.

\section{Phase inversion method}

According to ISO/TR6579 (2014), specific phase inversion antiserum was added to a swarm agar medium (SIFIN) and the Salmonella strain was spot inoculated on the plate. The agar medium shall be sufficiently soft for motile Salmonella to swarm over the medium. Slide agglutination test was performed from periphery of the plate after incubation at $37 \mathrm{C}^{\circ}$ for $24 \mathrm{hrs}$.

\section{Duplex Syber green real-time PCR}

For the detection of genus Salmonella and $S$. Typhimurium, DNA was extracted from the strains according to QIAamp DNA mini kit instructions (Soumet et al., 1999 and Yang et al., 2014). SYBR Green real-time PCR was performed using oligonucleotide primers (Table 1) and Quantitect SYBR green PCR kit containing $1 \mathrm{ml}$ 2xQuantiTect SYBR Green PCR Master Mix, 2ml RNaseFree Water.

Table 1.Oligonucleotide primers used in this study for detection of genus Salmonella using 16SrRNA and fliC genes

\begin{tabular}{lll}
\hline $\begin{array}{l}\text { Target } \\
\text { gene }\end{array}$ & Primer sequence (5'-3') & Reference \\
\hline $16 S$ & F: CAGAAGAAGCACCGGCTAACTC & Yang et al., \\
\cline { 2 - 2 }$r R N A$ & R: GCGCTTTACGCCCAGTAATT & 2014 \\
\hline \multirow{2}{*}{$f l i \mathrm{C}$} & F: CGGTGTTGCCCAGGTTGGTAAT & $\begin{array}{c}\text { Soumet et al., } \\
1999\end{array}$ \\
\cline { 2 - 3 } & R: ACTCTTGCTGGCGGTGCGACTT & \\
\hline
\end{tabular}

F: forward, R: reverse

Table 2. Oligonucleotide primers and probes used for differentiating between biphasic Salmonella Typhimurium and monophasic serovar 1, 4, [5], 12:i:- using fljBl,2 and $f l i B / I S 200$ in the $f l i A-f l i B$ intergenic region.

\begin{tabular}{|c|c|c|}
\hline Target & Primer sequence $\left(5^{\prime}-3\right.$ ') and probe & Reference \\
\hline \multirow{3}{*}{$f l j \mathrm{~B} 1,2$} & $\begin{array}{l}\text { F: TGT TAC TAT TGG TGG CTT TAC } \\
\text { TGG }\end{array}$ & \multirow{6}{*}{$\begin{array}{l}\text { Prendergast } \\
\text { et al., } 2013\end{array}$} \\
\hline & R: CAG CAG GCA TTG TGG TCT TAG & \\
\hline & $\begin{array}{l}\text { FAM- CGC CAG CCG CAA GGG TTA } \\
\text { CTG TAC - TAMRA }\end{array}$ & \\
\hline \multirow{3}{*}{$f l i B / 1 \mathrm{~S} 200$} & $\begin{array}{l}\text { F: GAT CTG TCG ATG ATT CAT CTT } \\
\text { CTG AC }\end{array}$ & \\
\hline & R: AAC GCT TGT CTT CGG TAT TTG G & \\
\hline & $\begin{array}{l}\text { CY5-TCG GGT GTG CGC TAA GCT CTT } \\
\text { TT -BHQ1 }\end{array}$ & \\
\hline
\end{tabular}

F: forward, R: reverse 
Differentiation of $S$. Typhimurium and monophasic 1, 4, [5], 12:i:-by TaqMan real-time PCR

TaqMan real-time PCR was performed according to Prendergast et al. (2013) using oligonucleotide primers and probes presented in table 2, and the Quantitect probe real-time PCR kit (Qiagen).

\section{fliC sequencing}

fliC was sequenced using $f l i C$ primer presented in table 1. A purified PCR product was sequenced in the way of the forward and/ or reverse directions on an Applied Biosystems 3130 automated DNA Sequencer (ABI, 3130, USA), using a ready reaction Bigdye Terminator V3.1 cycle sequencing kit (Perkin-Elmer/Applied Biosystems, Foster City, CA).

\section{Phylogenetic analysis}

A comparative analysis of sequences was performed using the CLUSTAL $\mathrm{W}$ multiple sequence alignment program, version 1.83 of MegAlign module of Lasergene DNA Star software Pairwise, which was designed by Thompson et al. (1994) and phylogenetic analyses were done using maximum likelihood, neighbor-joining and maximum parsimony in MEGA6 (Tamura et al., 2013).

\section{RESULTS}

\section{Serotyping of Salmonella}

The Serotyping of the 58 Salmonella strains was confirmed and the result is presented in table 3 .

Table 3. Antigenic structure of all Salmonella strains recovered using slide agglutination test.

\begin{tabular}{|c|c|c|c|c|c|}
\hline No & Name & Serotyping & No & Name & Serotyping \\
\hline $1-$ & S. Kentucky & $8,20: \mathrm{i}: z 6$ & $30-$ & S. Washington & $13,22: \mathrm{m}, \mathrm{t}:-$ \\
\hline $2-$ & S. Lagos & $1,4,5,12: \mathrm{i}: 1,5$ & $31-$ & S. Newport & $6,8,20: e, h: 1,2$ \\
\hline 3- & $S$. Typhimurium & $1,4,[5], 12: \mathrm{i}: 1,2$ & $32-$ & S. Enteritidis & $1,9,12: \mathrm{g}, \mathrm{m}:-$ \\
\hline 4- & $S$. Typhimurium & $1,4,[5], 12: \mathrm{i}: 1,2$ & $33-$ & S. Rissen & 6,7,14 :f,g:- \\
\hline 5- & S. Taksony & 1,3,19: i: $z_{6}$ & $34-$ & $S$. Labadi & $8,20: \mathrm{d}: \mathrm{z}_{6}$ \\
\hline 6- & $S$. Derby & 1,4,[5],12:f,g:- & $35-$ & S. Enteritidis & $1,9,12: \mathrm{g}, \mathrm{m}:-$ \\
\hline 7- & S. Rissen & 6,7,14:f,g:- & $36-$ & S. Senftenberg & 1,3,19: g,[s],t:- \\
\hline $8-$ & $S$. Typhimurium & $1,4,[5], 12: \mathrm{i}: 1,2$ & $37-$ & S. Cerro & $6,14,18: z 4, z 23:[1,5]$ \\
\hline $9-$ & $S$. Anatum & $3,\{10\}\{15\}\{15,34\}:$ e,h: 1,6 & $38-$ & S. Virginia & $8: d: 1,2$ \\
\hline $10-$ & S. Typhimurium & 1,4,[5],12:i:1,2 & $39-$ & S. Papuana & $6,7: \mathrm{r}: \mathrm{e}, \mathrm{n}, \mathrm{Z}_{15}$ \\
\hline $11-$ & $S$. Paratyphi A & 1,2,12: a: $[1,5]$ & $40-$ & S. Typhimurium & 1,4,[5],12:i:1,2 \\
\hline $12-$ & S. Paratyphi B & $1,4,[5], 12: b: 1,2$ & $41-$ & $S$. Typhimurium & 1,4,[5],12:i:1,2 \\
\hline $13-$ & S. Kedougou & $1,13,23:$ i :1,w & $42-$ & S. Kentucky & $8,20: \mathrm{i}: \mathrm{z}_{6}$ \\
\hline $14-$ & S. Labadi & $8,20: \mathrm{d}: \mathrm{z}_{6}$ & $43-$ & $S$. Typhimurium & $1,4,[5], 12: \mathrm{i}: 1,2$ \\
\hline $15-$ & S. Poona & $1,13,22: \mathrm{z}: 1,6$ & $44-$ & S. Enteritidis & $1,9,12: \mathrm{g}, \mathrm{m}:-$ \\
\hline 16- & $S$. Typhimurium & $1,4,[5], 12: \mathrm{i}: 1,2$ & $45-$ & S. Virginia & $8: \mathrm{d}: 1,2$ \\
\hline $17-$ & S. Kentucky & $8,20: \mathrm{i}: \mathrm{z}_{6}$ & $46-$ & S. Kentucky & $8,20: \mathrm{i}_{\mathrm{i}} \mathrm{Z}_{6}$ \\
\hline 18- & S. Anatum & $3,\{10\}\{15\}\{15,34\}$ :e,h: 1,6 & $47-$ & S. Washington & $13,22: \mathrm{m}, \mathrm{t}:-$ \\
\hline $19-$ & S. Goldcoast & $6,8: r$ :1,w & $48-$ & $S$. Enteritidis & 1,9,12:g,m: - \\
\hline $20-$ & $S$. Enteritidis & 1,9,12:g,m:- & $49-$ & $S$. Newlands & $3,\{10\}\{15,34\}: e, h e, n, x:-$ \\
\hline $21-$ & S. Infantis & $6,7,14: r: 1,5$ & $50-$ & S. Gallinarum & $1,9,12:-:-$ \\
\hline $22-$ & S. Gallinarum & $1,9,12:-:-$ & 51 & S. Agama & $4,12: \mathrm{i}: 1,6$ \\
\hline $23-$ & S. Gallinarum & $1,9,12:-:-$ & $52-$ & S. Kentucky & $8,20: \mathrm{i}: \mathrm{z}_{6}$ \\
\hline $24-$ & S. Hadar & $6,8: \mathrm{z}_{10}: \mathrm{e}, \mathrm{n}, \mathrm{x}$ & $53-$ & S. Kentucky & $8,20: \mathrm{i}: \mathrm{z}_{6}$ \\
\hline $25-$ & S. Virchow & $6,7,14: \mathrm{r}: 1,2$ & $54-$ & S. Typhimurium & 1,4,[5],12:i:1,2 \\
\hline $26-$ & S. Virchow & $6,7,14: \mathrm{r}: 1,2$ & $55-$ & S. Typhimurium & $1,4,[5], 12: \mathrm{i}: 1111,2$ \\
\hline $27-$ & S. Hadar & $6,8: z_{10}: e, n, x$ & $56-$ & S. Typhimurium & 1,4,[5],12:i:1,2 \\
\hline $28-$ & S. Bardo & $8: e, h: 1,2$ & $57-$ & Partial identification & 1,4,[5],12:i:- \\
\hline $29-$ & S. Montevideo & $6,7,14: \mathrm{g}, \mathrm{m}, \mathrm{s}:-$ & $58-$ & $S$. Typhimurium & $1,4,[5], 12: \mathrm{i}: 1,2$ \\
\hline
\end{tabular}




\section{Syber Green real-time duplex PCR}

All 58 strains belonged to genus Salmonella were positive by SYBER green real-time PCR using $16 S$ rRNA. The specificity of the reaction was confirmed by melting temperature $(\mathrm{Tm})$ which was consistently specific for amplicon obtained; the mean peaks Tm obtained. The negative control did not show peaks in the Tm when subjected to 40 cycles of amplification. Twenty-one Salmonella strains harbored $\mathrm{fliC}$ gene, including $S$. Typhimurium (12), S. Kentucky (6), $S$. Lagos (1), $S$. Kedougou (1) and partial identified strain $S$ 1,4, [5],12:i:which possess first flagellar i antigen (Table 4; figures 1 and 2). A total of 15 strains were positive for $f l j B$ 1,2. Ten strains of Salmonella Typhimurium and serovars Paratyphi A (1) \& Paratyphi B (1) \& Newport (1) and Virginia (2) harbored $f l j B 1,2$, while strain no.57 with antigenic formula 1, 4 ,[5], 12:i:- and two strains Salmonella Typhimurium lacked this gene. Concerning fli B/IS200, the 13 strains possess fliB/IS200 (12 S. Typhimurium and the variant strain S 1, 4 ,[5], 12:i:-) (Table 5 and figure 3).

\section{fli $C$ Sequencing}

Individual Salmonella serotypes usually alternate between the production of 2 antigenic forms of flagella, termed phase 1 and phase 2 , each specified by separate structural genes, $f l i C$ and $f l j B$ 1, 2. Sequencing of $f l i C$ gene based on the nucleotide sequence of $S$.Typhimurium13311 referenced in GenBank illustrated that the biphasic $S$. Typhimurium strain was recorded in GenBank as $S$. Typhimurium Egy 1 with accession number Mk103394 and the monophasic strain as $S$. Typhimurium Egy 2 with accession number MK 103395. The amino acid sequence of the $f l i C$ gene in the two isolates showing greater than $98 \%$ identity.

Table 4. Detection of $16 \mathrm{SrRNA}$ and fliC genes in Salmonella serovars using duplex Syber green real-time PCR

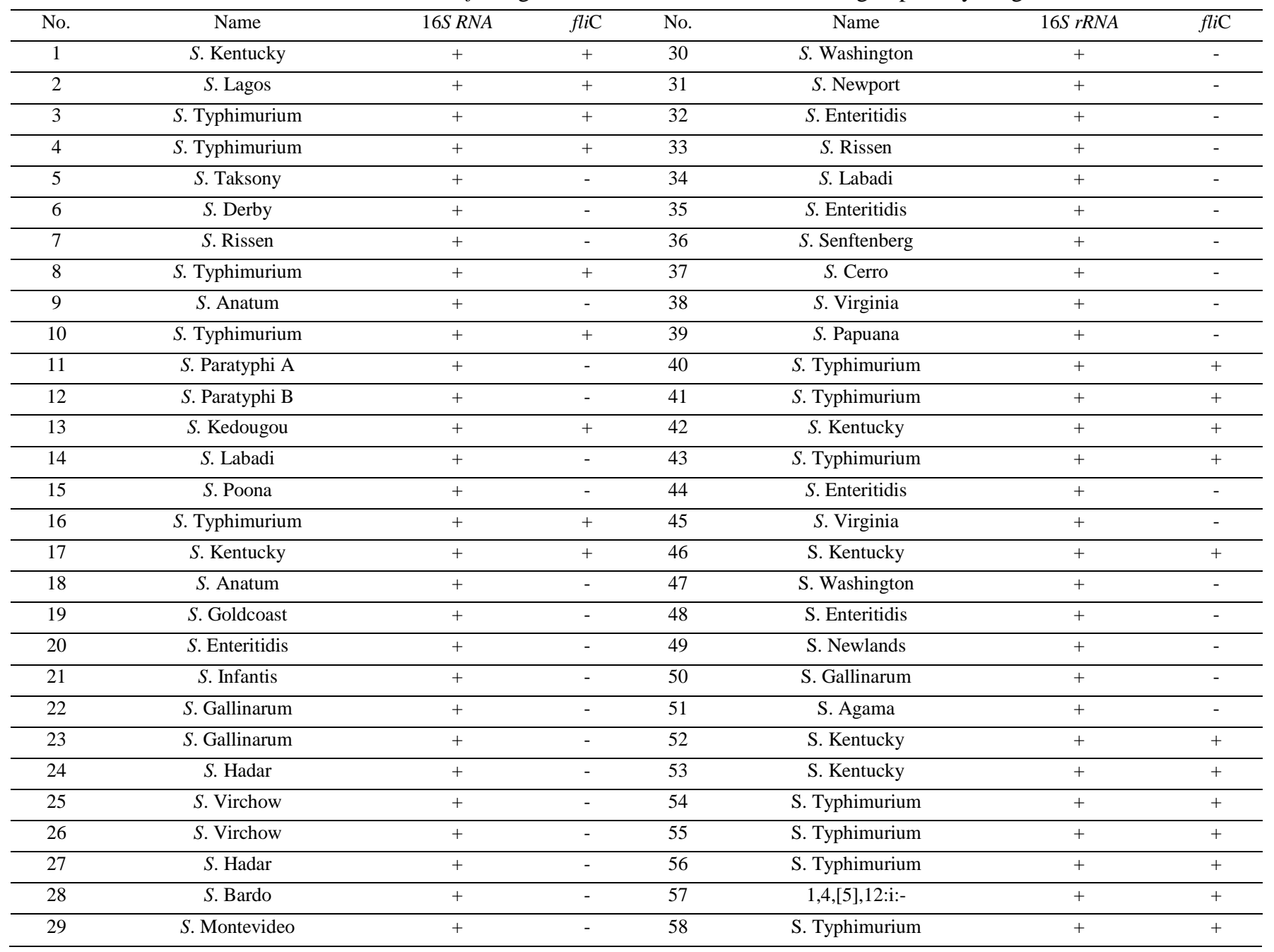


Table 5. Detection of $f l j B 1,2$ and $f l i B / I S 200$ in Salmonella serovars using duplex TaqMan real-time PCR

\begin{tabular}{|c|c|c|c|c|c|c|c|}
\hline No. & Name & $f l j B 1,2$ & fliB/IS200 & No. & Name & $f l j B 1,2$ & $\mathrm{fliB} / \mathrm{IS} 200$ \\
\hline 1 & S. Kentucky & - & ND & 30 & S. Washington & - & $\mathrm{ND}$ \\
\hline 2 & S. Lagos & - & ND & 31 & S. Newport & + & ND \\
\hline 3 & $S$. Typhimurium & + & + & 32 & $S$. Enteritidis & - & ND \\
\hline 4 & $S$.Typhimurium & + & + & 33 & $S$. Rissen & - & ND \\
\hline 5 & S. Taksony & - & ND & 34 & S. Labadi & - & ND \\
\hline 6 & $S$. Derby & - & $\mathrm{ND}$ & 35 & $S$. Enteritidis & - & ND \\
\hline 7 & $S$. Rissen & - & $\mathrm{ND}$ & 36 & S. Senftenberg & - & $\mathrm{ND}$ \\
\hline 8 & $S$. Typhimurium & + & + & 37 & S. Cerro & - & $\mathrm{ND}$ \\
\hline 9 & $S$. Anatum & - & $\mathrm{ND}$ & 38 & $S$. Virginia & + & ND \\
\hline 10 & $S$. Typhimurium & + & + & 39 & S. Papuana & - & ND \\
\hline 11 & S. Paratyphi A & + & ND & 40 & $S$. Typhimurium & + & + \\
\hline 12 & S. Paratyphi B & + & ND & 41 & $S$. Typhimurium & + & + \\
\hline 13 & $S$. Kedougou & - & $\mathrm{ND}$ & 42 & $S$. Kentucky & - & $\mathrm{ND}$ \\
\hline 14 & S. Labadi & - & $\mathrm{ND}$ & 43 & S. Typhimurium & + & + \\
\hline 15 & $S$. Poona & - & ND & 44 & $S$. Enteritidis & - & ND \\
\hline 16 & $S$. Typhimurium & + & + & 45 & $S$. Virginia & + & $\mathrm{ND}$ \\
\hline 17 & S. Kentucky & - & ND & 46 & S. Kentucky & - & ND \\
\hline 18 & S. Anatum & - & $\mathrm{ND}$ & 47 & S. Washington & - & $\mathrm{ND}$ \\
\hline 19 & S. Goldcoast & - & ND & 48 & $S$. Enteritidis & - & ND \\
\hline 20 & $S$. Enteritidis & - & ND & 49 & S. Newlands & - & ND \\
\hline 21 & $S$. Infantis & - & ND & 50 & S. Gallinarum & - & ND \\
\hline 22 & S. Gallinarum & - & ND & 51 & S. Agama & - & ND \\
\hline 23 & S. Gallinarum & - & ND & 52 & S. Kentucky & - & ND \\
\hline 24 & S. Hadar & - & ND & 53 & S. Kentucky & - & ND \\
\hline 25 & S. Virchow & - & $\mathrm{ND}$ & 54 & S. Typhimurium & + & + \\
\hline 26 & S. Virchow & - & $\mathrm{ND}$ & 55 & S. Typhimurium & - & + \\
\hline 27 & $S$. Hadar & - & $\mathrm{ND}$ & 56 & $S$. Typhimurium & - & + \\
\hline 28 & S. Bardo & - & $\mathrm{ND}$ & 57 & S. Typhimurium & - & + \\
\hline 29 & S. Montevideo & - & ND & 58 & S. Typhimurium & + & + \\
\hline
\end{tabular}

ND: Not detected 

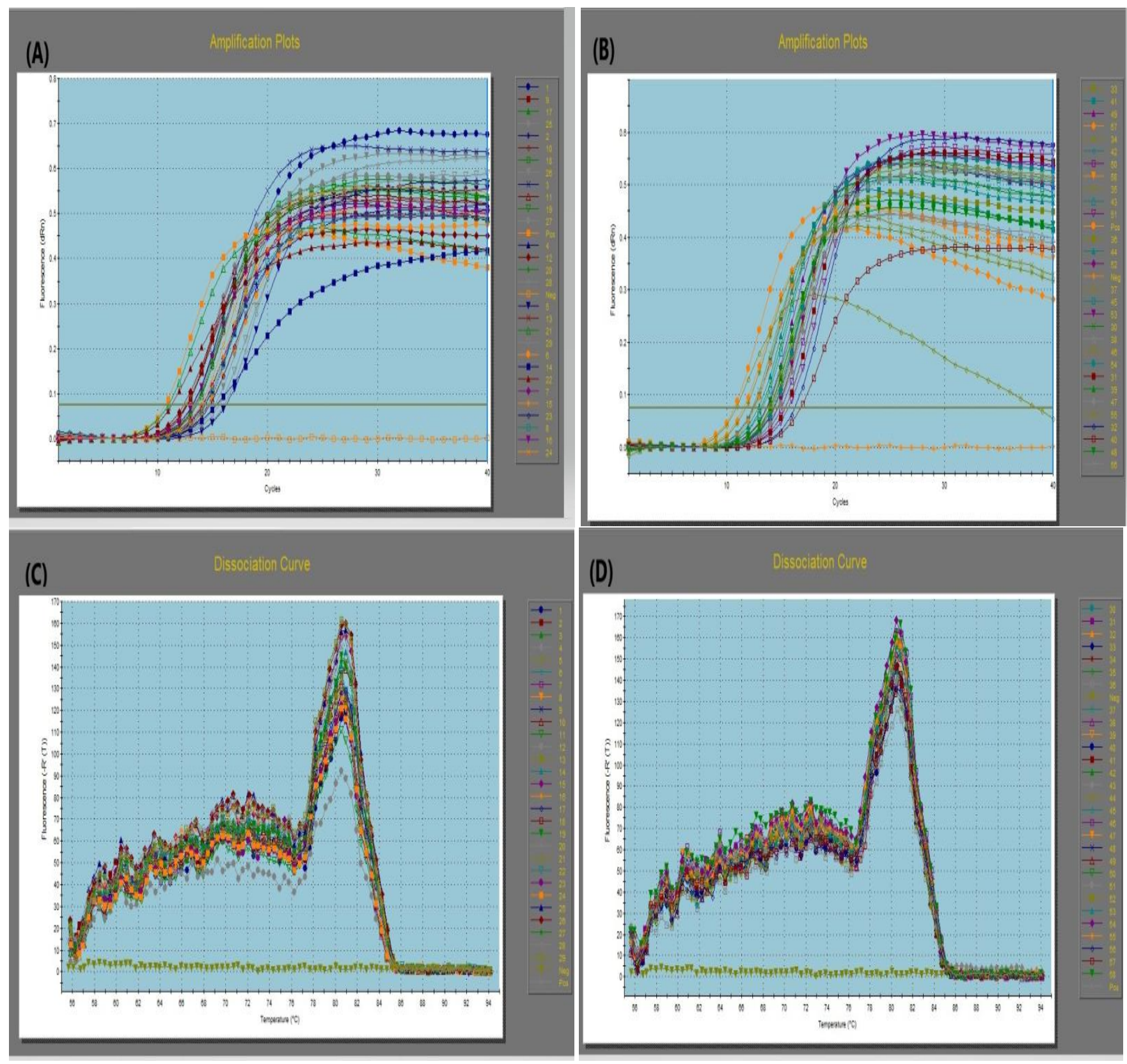

Figure 1. Syber green real-time PCR targeting $16 \mathrm{~S}$ rRNA gene for 58 Salmonella strains isolated from chickens (fluorescence chart and melting curve). A) Fluorescence chart for strains number 1 to 29. B) Fluorescence chart for strains number 30 to 58. (Amplification plots represent the accumulation of product over the duration of real-time PCR). C) Melting curve for strain number 1 to 29. D) Melting curve for strain number 30 to 58. Melting curve provides representation of the PCR product after the amplification process, A single peak indicates a positive sample. All 58 strains isolated from chickens were positive for 16SrRNA gene. The specificity of the reaction was confirmed by the melting temperature. The mean peak temperature obtained was $80.55^{\circ} \mathrm{C}$. 

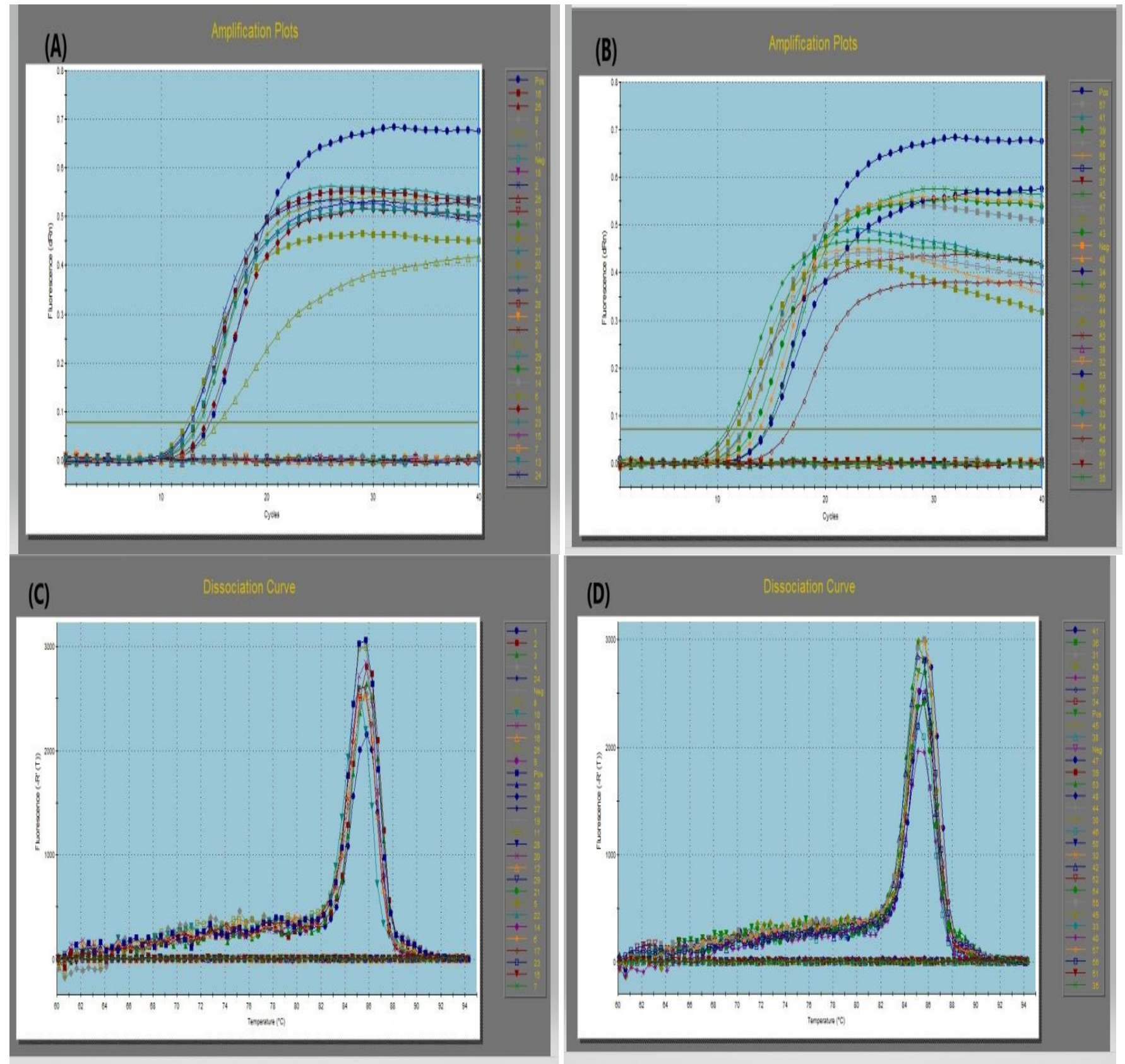

Figure 2. Syber green real-time PCR targeting fliC gene for 58 Salmonella strains isolated from chicken (fluorescence chart and melting curve). A) Fluorescence chart for strains number 1 to 29. B) Fluorescence chart for strains number 30 to 58 (Amplification plots represent the accumulation of product over the duration of real-time PCR). C) Melting curve for strain number 1 to 29, where strains number 1, 2, 3, 4, 8, 10,13, 16 and 17 gave positive results. D) Melting curve for strain number 30 to 58, where strains number 40, 41, 42, 43, 46, 52, 53, 54, 55, 56, 57 and 58 gave positive result . (Melting curve provide representation of the PCR product after the amplification process. A single peak indicates a positive sample. Twenty-one Salmonella strains harbored fliC gene. The specificity of the reaction was confirmed by melting temperature, the mean peak temperature obtained was $85.65^{\circ} \mathrm{C}$. 


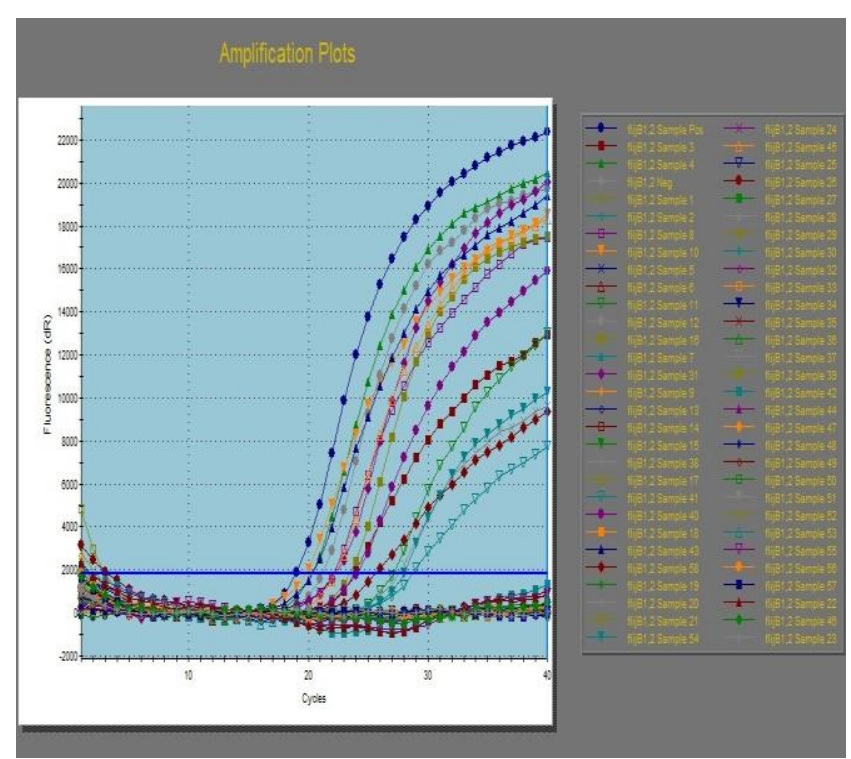

Figure 3. TaqMan real-time PCR amplification chart for fljB1,2 gene among 58 Salmonella strains isolated from chickens. Typical amplification curves given for positive samples. Fifteen strains (number 3, 4, 8, 10, 11, 12, 16, 31, $38,40,41,43,45,54$ and 58) gave positive results.

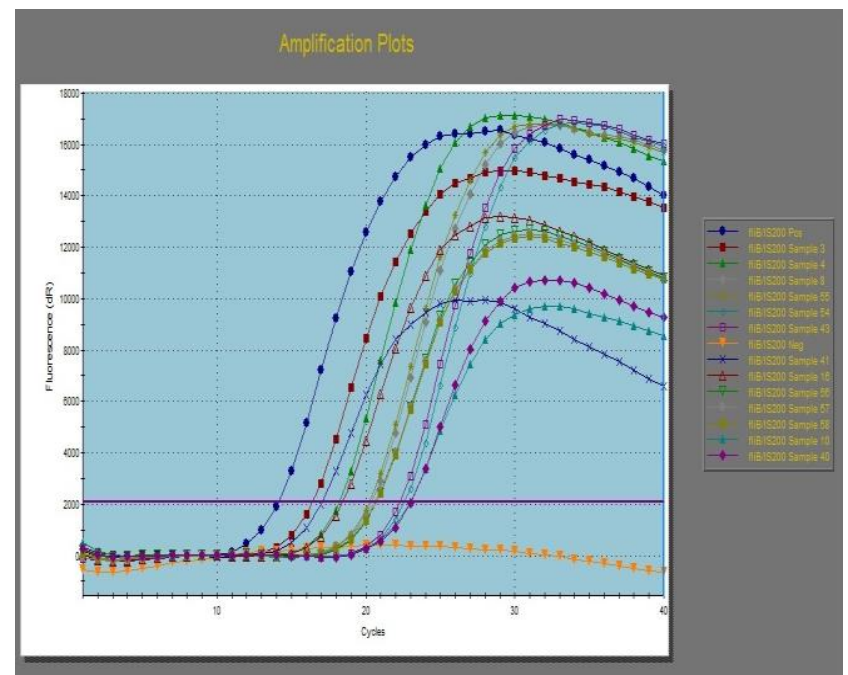

Figure 4. TaqMan real-time PCR amplification chart for fliB/IS200 gene among 13 Salmonella isolates (12 S. Typhimurium and the variant strain serotype 1, 4, [5], 12:i:-) (fliB/IS200 is $a$ specific gene for $S$. Typhimurium biphasic and monophasic ). Thirteen strains (number 3,4 , $8,10,16,40,41,43,54,55,56,57$ and 58) gave positive results.

\section{DISCUSSION}

Serological identification of 58 Salmonella strains was confirmed by slide agglutination test and the antigenic structure is demonstrated in table 3. Failure to identify the complete antigenic formula prevents the unequivocal identification of serovars even after phase inversion method. The strain was considered monophasic when phase inversion method was repeated at least three times without getting expression of phase 2 flagellar antigen as shown in strain number 57 with antigenic formula S.1, 4, [5], 12:i:-. Grimont and Weil (2007) mentioned that $S .1,4$, [5], 12:i:- does not appear in the White-Kaufmann-Le Minor scheme and appears to be a monophasic variant of other biphasic serovars, which have lost phase 2 flagellin or the necessary switching mechanism of phase variation. Seven serovars of $S$. enterica subsp. enterica with the same $\mathrm{O}$ and phase $1 \mathrm{H}$ antigens are possible ancestors of this serovar, including $S$. Typhimurium, $S$. Lagos, $S$. Agama, $S$. Farsta, $S$. Tsevie, $S$. Gloucester, and $S$. Tumodi. Among these, $S$. Typhimurium monophasic S.1, 4, [5], 12:i:- is commonly isolated from humans, animals, and the environment.

In recent years, many studies try to establish methods that can reduce the time for the detection and identification of salmonellae. Detection of bacteria by conventional methods is time-consuming and allows the detection of viable one only (Kim et al., 2006).

The use of PCR has emerged as an approach to overcome these problems. The exploration of gene targets for evaluation of absence and presence of bacteria is still a matter of importance. Several genes invA, fimA, and aceK were used for identification of genus Salmonella (O'Regan et al., 2008). The duplex Syber green real-time PCR was applied for detection of genus Salmonella and the most common serovar $S$. Typhimurium based on melting Temp (TM) and Curve analysis using $16 S$ rRNA and fli $C$ genes respectively. $16 S$ rRNA not only allow the presence of bacteria to be proved but also would give information on gene expression .However, the expression of rRNA is tightly depend on physiological status of bacteria (Imre et al., 2005). In this study all 58 Salmonella strains harbor 16 $S$ rRNA (Table 4 and figure 1).

16SrRNA gene sequences contain hypervariable regions that can allow species-specific signature sequences important for identification of bacteria. The $16 \operatorname{SrRNA}$ gene is used as the standard for classification and identification of bacteria because it is present in most microbes and shows proper changes. 16 SrRNA gene sequences for most bacteria are available on public databases such as NCBI (Pereira, 2010). Attractive potential uses of $16 \mathrm{~S} r R N A$ gene sequence informatics for providing genus and species identification.

The $f l i C$ target is specific for the phase-1 flagellar antigen i that encoded by serovars Typhimurium. In the present study twenty one strains possess fliC gene serovars Typhimurium (12), Kentucky (6), Kedougou (1), Lagos 
(1) and $S .1,4$, [5], 12:i:-.(1) (Table 4 and figure 2). O' Regan et al. (2008) reported that the $\mathrm{i}$ antigen is also expressed in uncommon serotypes such as Aberdeen, Bergen, and Kedougou. The structural flagellin gene $f l i C$ was present in all isolates of serovars Typhimurium and Kentucky (full length) and in all isolates of serovars Heidelberg, Hadar, and Enteritidis (partial length) (Dhanani et al., 2015).

Most S. enterica serovar Typhimurium possess two different flagellin proteins, including FliC (phase 1) and FljB (phase 2), which are encoded by the genes $f l i C$ and $f l j B$, respectively. European Food Safety Authority (EFSA) (2010) applied a conventional PCR protocol to confirm the absence of $2^{\text {nd }}$ phase antigen. A real- time PCR assay was used to differentiate $S$. Typhimurium monophasic variants from biphasic $S$. Typhimurium and from other variants (Anon, 2010; Tennant et al., 2010).

Fifteen isolates are positive for $f l j B 1,2 S$. Typhimurium (10), S. Paratyphi A(1), $S$. Paratyphi B(1), $S$. Newport (1) and $S$. Virginia (2) (Table 5 and figure 3). This result agree with that published by Bugarel et al. (2012) who reported that the second gene codes for the phase 2 flagellar antigen $f l j B 1,2$ is present in $S$. Typhimurium and other serovars such as $S$. Coeln, $S$. Haifa, $S$. Heidelberg, $S$. Paratyphi B, $S$. Saintpaul and $S$. Stanley. This marker is absent in monophasic $S$. Typhimurium. Two serologically identified $S$. Typhimurium strains no. 55,56 don't possess $f l j B 1,2$ that could be explained by repeat phase inverted method leads to formation of flakes which may lead to misidentification or wrongly identified strains.

Flagellar phase variation is formed by inversion of the genetic region called the $\mathrm{H}$ segment, which have the hin gene encoding for DNA invertase and the promoter for the $f l j B$ gene. The $f l j B$ constitutes an operon with the $f l j A$ gene, which encodes a negative regulator of $\mathrm{fliC}$ expression. FljA binds to the operator region of FliC mRNA and inhibits its translation, leading to the rapid degradation of FliC mRNA. When the $\mathrm{H}$ segment is in the "on" state, both $f l j B$ and $f l j A$ are transcribed, lead to synthesis of phase 2 flagellin and inhibition of phase 1 flagellin. However, when the $\mathrm{H}$ segment is switched to the "off" state, neither $f l j B$ nor $f l j A$ are transcribed, resulting in the synthesis of phase 1 flagellin only (Ido et al., 2014).

The location of IS200 between the genes fliA and $f l i B$ can be used as a specific marker for $S$. Typhimurium. The amplicon sizes from the fliA-fliB intergenic regions from $S$. Typhimurium and other serovars were expected to be 1000 and $250 \mathrm{bp}$, respectively. TaqMan real-time PCR could successfully detected $S$. 1, 4, [5], 12:i:- isolates that yield1000-bp amplicon with conventional PCR. These data suggest that $S$. 1, 4, [5], 12:i:- is a monophasic variant of $S$. Typhimurium (Burnens et al., 1997). Also, they reported that within the flagellin gene cluster of Salmonella, S. Typhimurium carries a conserved IS200 insertion sequence located downstream of the flagellin $\mathrm{N}$ methylase gene (fliB) and upstream of the flagellar biosynthesis sigma factor gene $(f l i \mathrm{~A})$. In the present study ten strains yield positive result with $f l i C$, $f l j B 1,2$ and $f l i B /$ IS200 were biphasic Salmonella Typhimurium meanwhile 3 strains harbored the $f l i C$ and $f l i B /$ IS200 were monophasic strains $S$ 1, 4,[5],12:i:- (Table 6) .

During recent years the cost of sequencing has been reduced dramatically making sequencing based typing more attractive. Some studies have reported DNA sequence for flagellin gene (Silverman, 1979; Joys, 1985 and De Vries, 1998). As in 2016, fliC sequence (partial coding sequence) has reported in GenBank with accession no DQ095491. This study reported sequencing of fliC gene for two strains $S$. Typhimurium and monophasic variant $S$ 1, 4,[5],12:i:- with accession no (Mk103394) and (Mk103395), respectively.

Protein sequence is the practical process of determining the amino acid sequence of all or part of protein or peptide. About 500 naturally occurring amino acids are known, 20 only appear in the genetic code there are termed as codons are always 3 Base pairs (nucleotides). In this study, amino acid sequence were applied for the fliC gene. In the location 14-19 sequence TNGKVT was found, which is similar to sequences coded in GenBank with accession no. CP024619, LT795114, CP014979, but in other sequences reported in GenBank with accession no. CP026700, CP021462, CP028199 glutamic acid was found between GK with amino acid sequence TNGEKVT (Figure 5).

In this study, the amino acid threonine was absent at position 24 in $S$. Typhimurium Egy1 and $S$. Typhimurium Egy2, which is similar to sequences recorded in GenBank with accession no. CP014979, CP014967. While the result disagreed with sequences coded in GenBank with accession number CP007581 and DQ09549 which have threonine at position 24 between glycine and alanine.

At position 60-65 found amino acid sequence AGVTGT in $S$. Typhimurium Egy1 and $S$. Typhimurium Egy2, but in sequence coded in GenBank with accession no. LN999997 amino acid alanine at positin 65 between glysine and threonine was found. Alignments show highly degree of identity. There are greater than $98 \%$ amino acid sequence identity (Figures 6 and 7). This is according to Sandjong et al. (2007). 
Table 6. Comparison between results of conventional serotyping and real-time PCR for Salmonella Typhimurium (biphasic and monophasic strains)

\begin{tabular}{|c|c|c|c|c|c|c|c|}
\hline \multirow[b]{2}{*}{ No. of isolate } & \multirow[b]{2}{*}{ Name of isolate } & \multicolumn{3}{|c|}{ Conventional serotyping } & \multicolumn{3}{|c|}{ Real -time PCR } \\
\hline & & $O$ antigen & $\begin{array}{c}\text { Phase } 1 \mathrm{H} \\
\text { antigen }\end{array}$ & $\begin{array}{c}\text { Phase } 2 \mathrm{H} \\
\text { antigen }\end{array}$ & $f l i C$ & $f l j B 1,2$ & fliB/IS200 \\
\hline 10 strains & $\begin{array}{l}\text { Salmonella Typhimurium } \\
\text { (diphasic) }\end{array}$ & $4,[5], 12$ & I & 1,2 & + & + & + \\
\hline 3 strains & $\begin{array}{c}\text { Salmonella Typhimurium } \\
\text { monophasic) }\end{array}$ & $4,[5], 12$ & I & $\begin{array}{c}\text { Not } \\
\text { detected }\end{array}$ & + & - & + \\
\hline 1 strain & $\begin{array}{l}\text { Non-Salmonella } \\
\text { Typhimurium }\end{array}$ & $4,[5], 12$ & $\mathrm{I}$ & & + & - & - \\
\hline 5strains & $\begin{array}{l}\text { Non Salmonella } \\
\text { Typhimurium }\end{array}$ & $4,[5], 12$ & - & 1,2 & - & + & - \\
\hline
\end{tabular}

Majority

CPeø9102.1 S. Typhimurium strain 13311

S. Typhimurium Egy 1

S. Typhimurium Egy 2

CP024619.1 S. Typhimurium BL10

LT795114.1 S. Typhimurium VNB151

CP014979.2 S. Typhimurium CDC H2662

CP019442.1 S. Typhimurium 81741

CP014969.1 S. Typhimurium USDA-ARS-USMA

CP014967.1 S. Typhimurium CDC2011K-1702

CP012985.1 S. Typhimurium RM9437

CP012681.1 S. Typhimurium 33676

AY649718.1 S. Typhimurium SGSC2193

CP021462.1 S. Typhimurium UGA14e

CP028199.1 S. Typhimurium CFSANe18746

CP026700.1 S. Typhimurium AR_0031

LT855376.1 S. Typhimurium STMU2UK.

CP013720.1 S. Typhimurium RM10607

CP002487.1 S. Typhimurium ST4/74

HM920247.1 S. Typhimurium IVRI

AP011957.1 S. Typhimurium Te00240

FQ312003.1 S. Typhimurium SL1344

CP001363.1 S. Typhimurium $14028 \mathrm{~S}$

EF599295.1 S. Typhimurium 95

DQQ95487.1 S. Typhimurium LT 2

LN999997.1 S. Typhinurium S04698-09 I

CP007581.1 S. Typhimurium 138736

DQe95491.1 S. Typhimurium 50591703

\section{TGKDGYYEVSVOKTNGKVTLAGGATSPLTGGLPATATEDVKNVQVANADLTEAKAALTAAGVTGTASWKMSYTDNNGKT}

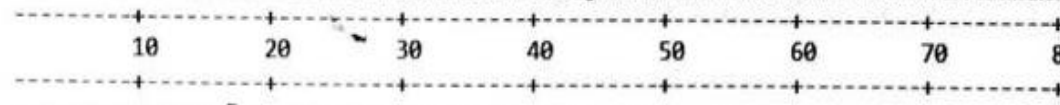

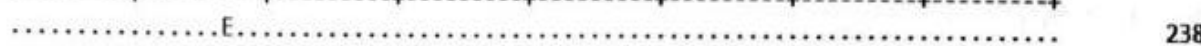

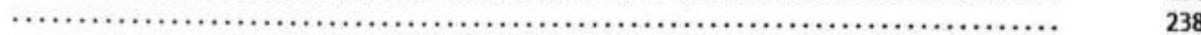

. . . . . .

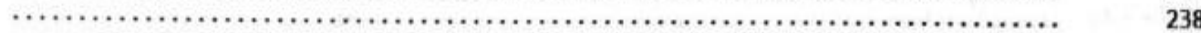

...........

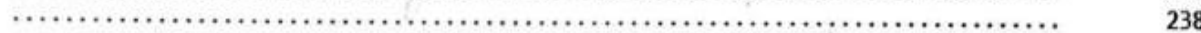

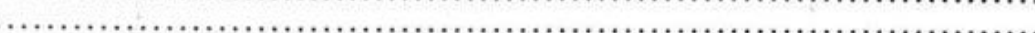

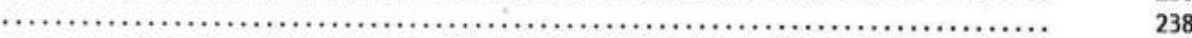

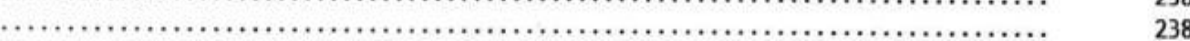

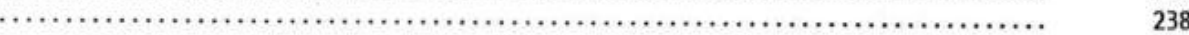

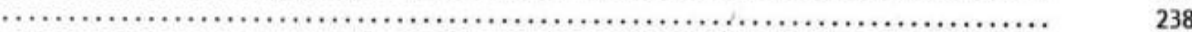

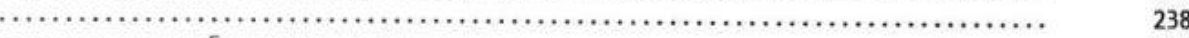

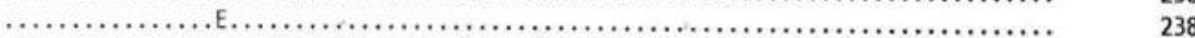

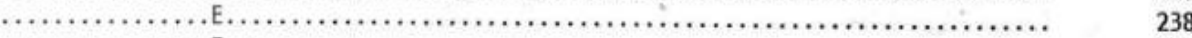

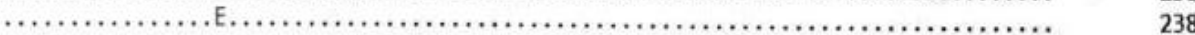

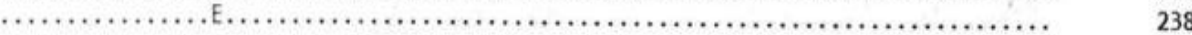

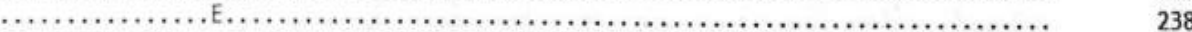

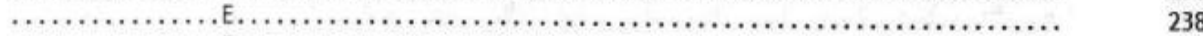

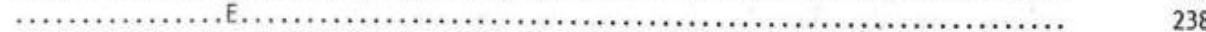

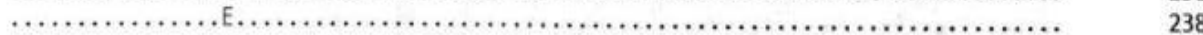

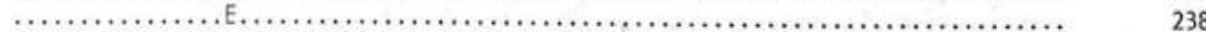

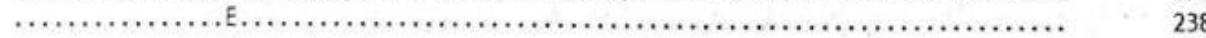

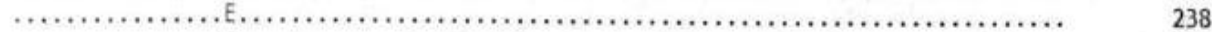

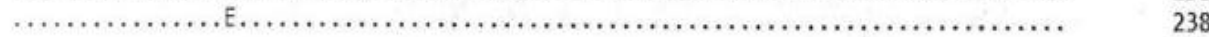

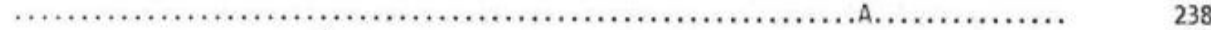

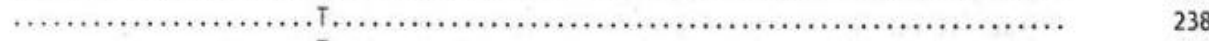

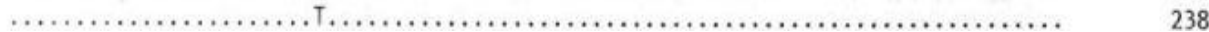




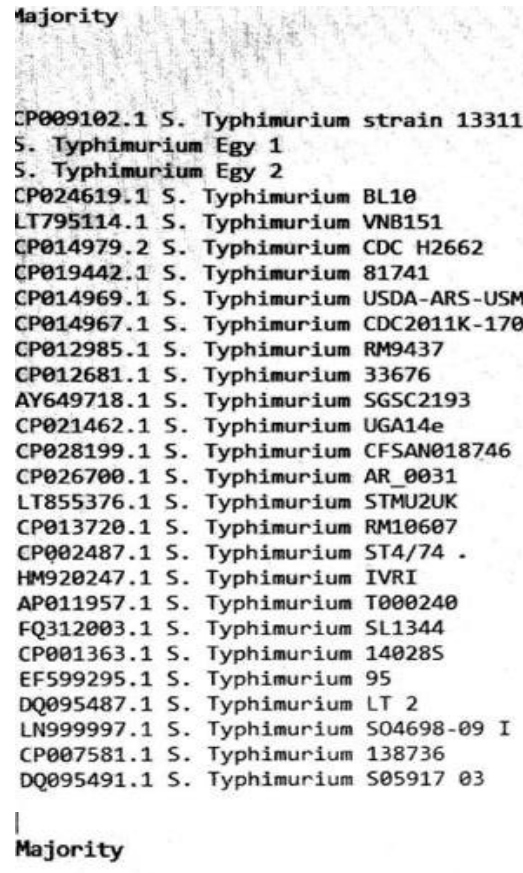

CPeø9102.1 S. Typhimurium strain 13311 S. Typhimurium Egy 1 5. Typhimurium Egy 2 CP024619.1 S. Typhimurium BL10 LT795114.1 S. Typhimurium VNB151 CP014979.2 S. Typhimurium CDC H2662 CPE19442.1 S. Typhimurium 81741 CP014969.1 S. Typhimurium USDA-ARS-USMA CP014967.1 S. Typhimurium CDC2011K-1702 CP012985.1 S. Typhimurium RM9437 CP012681.1 S. Typhimurium 33676 AY649718.1 S. Typhimurium SGSC2193 CP021462.1 S. Typhimurium UGA14e CPQ28199.1 S. Typhimurium CFSANO18746 CP026700.1 S. Typhimurium AR_0031 LT855376.1 S. Typhimurium STMU2UK CP013720.1 S. Typhimurium RM10607 CP002487.1 S. Typhimurium ST4/74 HM920247.1 S. Typhimurium IVRI AP011957.1 S. Typhimurium T000240 FQ312003.1 S. Typhimurium SL1344 CP001363.1 S. Typhimurium $14028 \mathrm{~S}$ EF599295.1 S. Typhimurium 95 DQ095487.1 S. Typhimurium LT 2 LN999997.1 S. Typhimurium S04698-09 I CP007581.1 S. Typhimurium 138736 DQ995491.1 S. Typhimurium S05917 03
IDGGLAVKVGDDYYSATONKDGSISINTTKYTADDGTSKTALNKLGGADGKTEWSIGGKTYAASKAEGHNFKAQPDLAE

\begin{tabular}{|c|c|c|c|c|c|c|}
\hline 90 & 100 & 110 & $12 \theta$ & 130 & 140 & 150 \\
\hline
\end{tabular}

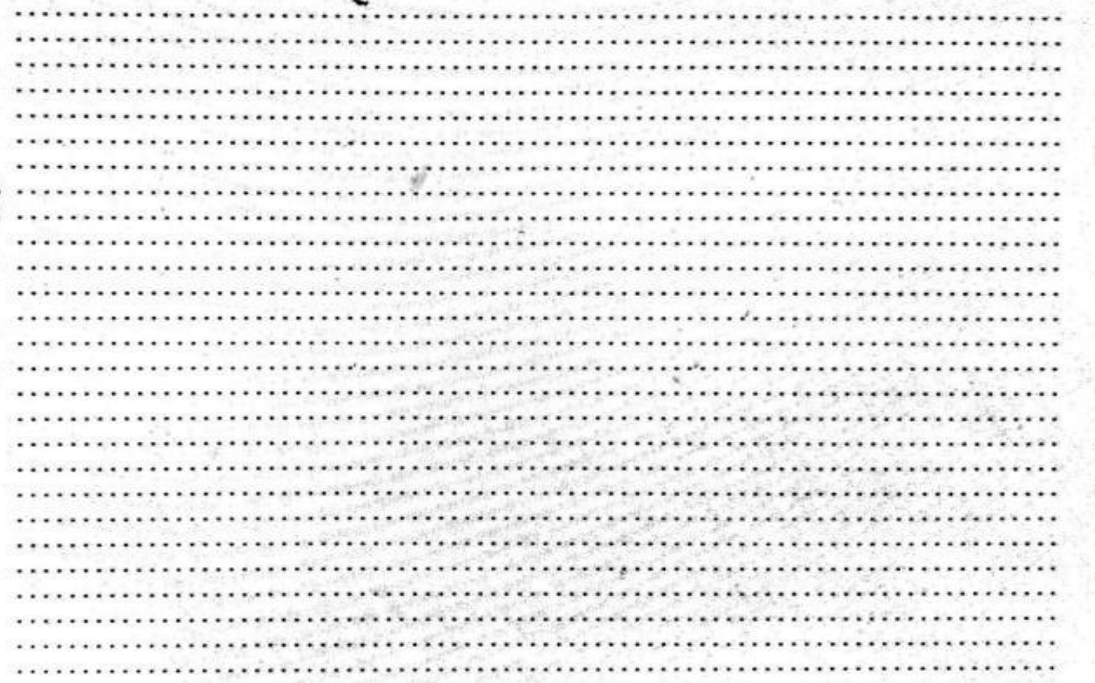

AAATTENPLQKIDAALAQVDTLRSD̀TGAVQNRFNSAITNLGNT

$\begin{array}{cccc}170 & 180 & 190 & 200 \\ - & -190\end{array}$

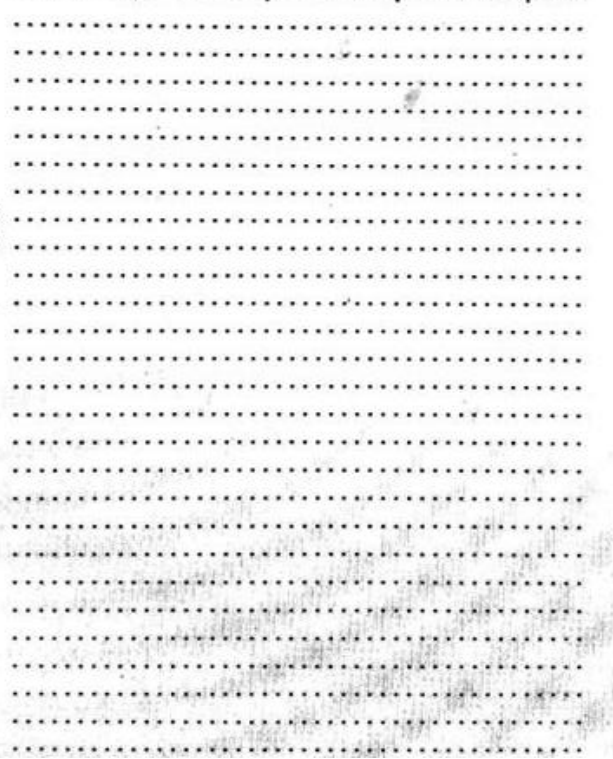

Figure 5. Amino acid sequence alignment report for fliC gene of two Egyptian Salmonella strains recorded in GenBank with accession number Mk103394 and Mk103395 for $S$. Typhimurium Egy 1(biphasic) and S. Typhimurium Egy 2 (monophasic), respectively. The sequence alignment of two Egyptian strains is 100\% similar to nine strains recorded in GenBank ( $S$. Typhimurium BL10, S. Typhimurium VNB151 , S. Typhimurium CDC H2662, S. Typhimurium 81741, S. Typhimurium USDA-ARS-USMA, $S$. Typhimurium CDC2011K-1702, S. Typhimurium RM9437, S. Typhimurium 33676 and $S$. Typhimurium SGSC2193). In the location 14-19, sequence TNGKVT was found for two Egyptian strains that matched sequences of some strains coded in GenBank with accession no. CP024619, LT795114, and CP014979, but in other strains reported in GenBank with accession no. CP026700, CP021462, and CP028199 glutamic acid was found between GK and amino acid sequence was TNGEKVT. The amino acid threonine was absent at position 24 in $S$. Typhimurium Egy1 and $S$. Typhimurium Egy2, but strains recorded in GenBank with accession no. CP007581 and DQ09549 have threonine at position 24 between glycine and alanine. At position 60-65 aminoacid sequence AGVTGT was found in $S$. Typhimurium Egy1 and $S$. Typhimurium Egy2, but in a sequence coded in GenBank with accession no. LN999997 amino acid alanine was found at position 65 between glycine and threonine. 
Percent Identity

\begin{tabular}{|c|c|c|c|c|c|c|c|c|c|c|c|c|c|c|c|c|c|c|c|c|c|c|c|c|c|c|c|c|}
\hline & 1 & 2 & 3 & 4 & 5 & 6 & 7 & 8 & 9 & 10 & 11 & 12 & 13 & 14 & 15 & 16 & 17 & 18 & 19 & 20 & 21 & 22 & 23 & 24 & 25 & 26 & 27 & \\
\hline 1 & & 99.8 & 99.8 & 99.8 & 99.8 & 99.8 & 99.8 & 99.8 & 99.8 & 99.8 & 99.8 & 99.8 & 100.0 & 100.0 & 100.0 & 100.0 & 100.0 & 100.0 & 100.0 & 100.0 & 100.0 & 100.0 & 100.0 & 100.0 & 99.7 & 99.7 & 99.7 & 1 \\
\hline 2 & 0.2 & & 100.0 & 100.0 & 100.0 & 100.0 & 100.0 & 100.0 & 100.0 & 100.0 & 100.0 & 100.0 & 99.8 & 99.8 & 99.8 & 99.8 & $\begin{array}{l}99.8 \\
\end{array}$ & 99.8 & 99.8 & 99.8 & 99.8 & 99.8 & 99.8 & 99.8 & 99.8 & 99.8 & 9.8 & 2 \\
\hline 3 & 0.2 & 0.0 & & 100.0 & 100.0 & 100.0 & 100.0 & 100.0 & 100.0 & 100.0 & 100.0 & 100.0 & 99.8 & 99.8 & 99.8 & 99.8 & $\begin{array}{l}99.8 \\
\end{array}$ & 99.8 & 99.8 & \begin{tabular}{|l|}
99.8 \\
\end{tabular} & 99.8 & \begin{tabular}{|l|}
99.8 \\
\end{tabular} & 99.8 & 99.8 & 99.8 & 99.8 & 99.8 & 3 \\
\hline 4 & 0.2 & 0.0 & 0.0 & & 100.0 & 100.0 & 100.0 & 100.0 & 100.0 & 100.0 & 100.0 & 100.0 & 99.8 & 99.8 & 99.8 & 99.8 & 99.8 & 99.8 & 99.8 & 99.8 & 99.8 & 99.8 & 99.8 & 99.8 & 99.8 & 99.8 & 99.8 & 4 \\
\hline 5 & 0.2 & 0.0 & 0.0 & 0.0 & & 100.0 & 100.0 & 100.0 & 100.0 & 100.0 & 100.0 & 100.0 & 99.8 & 99.8 & 99.8 & 99.8 & 99.8 & 99.8 & 99.8 & 99.8 & 99.8 & 99.8 & 99.8 & 99.8 & 99.8 & 99.8 & 99.8 & 5 \\
\hline 6 & 0.2 & 0.0 & 0.0 & 0.0 & 0.0 & & 100.0 & 100.0 & 100.0 & 100.0 & 100.0 & 100.0 & 99.8 & 99.8 & 99.8 & 99.8 & 99.8 & 99.8 & 99.8 & 99.8 & 99.8 & 99.8 & 99.8 & 99.8 & 99.8 & 99.8 & 99.8 & 6 \\
\hline 7 & 0.2 & 0.0 & 0.0 & 0.0 & 0.0 & 0.0 & & 100.0 & 100.0 & 100.0 & 100.0 & 100.0 & 99.8 & 99.8 & 99.8 & 99.8 & 99.8 & 99.8 & 99.8 & 99.8 & 99.8 & 99.8 & 99.8 & 99.8 & 99.8 & 99.8 & 99.8 & 7 \\
\hline 8 & 0.2 & 0.0 & 0.0 & 0.0 & 0.0 & 0.0 & 0.0 & & 100.0 & 100.0 & 100.0 & 100.0 & 99.8 & 99.8 & 99.8 & 99.8 & 99.8 & 99.8 & 99.8 & 99.8 & 99.8 & 99.8 & 99.8 & 99.8 & 99.8 & 99.8 & 99.8 & 8 \\
\hline 9 & 0.2 & 0.0 & 0.0 & 0.0 & 0.0 & 0.0 & 0.0 & 0.0 & & 100.0 & 100.0 & 100.0 & 99.8 & 99.8 & 99.8 & 99.8 & 99.8 & 99.8 & 99.8 & 99.8 & 99.8 & 99.8 & 99.8 & 99.8 & 99.8 & 99.8 & 99.8 & 9 \\
\hline 10 & 0.2 & 0.0 & 0.0 & 0.0 & 0.0 & 0.0 & 0.0 & 0.0 & 0.0 & & 100.0 & 100.0 & 99.8 & 99.8 & 99.8 & 99.8 & 99.8 & 99.8 & 99.8 & 99.8 & 99.8 & 99.8 & 99.8 & 99.8 & 99.8 & 99.8 & 99.8 & 10 \\
\hline 11 & 0.2 & 0.0 & 0.0 & 0.0 & 0.0 & 0.0 & 0.0 & 0.0 & 0.0 & 0.0 & & 100.0 & 99.8 & 99.8 & 99.8 & 99.8 & 99.8 & 99.8 & 99.8 & 99.8 & 99.8 & 99.8 & 99.8 & 99.8 & 99.8 & 99.8 & 99.8 & 11 \\
\hline 12 & 0.2 & 0.0 & 0.0 & 0.0 & 0.0 & 0.0 & 0.0 & 0.0 & 0.0 & 0.0 & 0.0 & & |99.8 & 99.8 & 99.8 & 99.8 & 99.8 & 99.8 & 99.8 & 99.8 & 99.8 & 99.8 & 99.8 & 99.8 & 99.8 & 99.8 & 99.8 & 12 \\
\hline 13 & 0.0 & 0.2 & 0.2 & 0.2 & 0.2 & 0.2 & 0.2 & 0.2 & 0.2 & 0.2 & 0.2 & 0.2 & & 100.0 & 100.0 & 100.0 & 100.0 & 100.0 & 100.0 & 100.0 & 100.0 & 100.0 & 100.0 & 100.0 & 99.7 & 99.7 & 99.7 & 13 \\
\hline 14 & 0.0 & 0.2 & 0.2 & 0.2 & 0.2 & 0.2 & 0.2 & 0.2 & 0.2 & 0.2 & 0.2 & 0.2 & 0.0 & & 100.0 & 100.0 & 100.0 & 100.0 & 100.0 & 100.0 & 100.0 & 100.0 & 100.0 & 100.0 & 99.7 & 99.7 & 99.7 & 14 \\
\hline 15 & 0.0 & 0.2 & 0.2 & 0.2 & 0.2 & 0.2 & 0.2 & 0.2 & 0.2 & 0.2 & 0.2 & 0.2 & 0.0 & 0.0 & & 100.0 & 100.0 & 100.0 & 100.0 & 100.0 & 100.0 & 100.0 & 100.0 & 100.0 & 99.7 & 99.7 & 99.7 & 15 \\
\hline 16 & 0.0 & 0.2 & 0.2 & 0.2 & 0.2 & 0.2 & 0.2 & 0.2 & 0.2 & 0.2 & 0.2 & 0.2 & 0.0 & 0.0 & 0.0 & & 100.0 & 100.0 & 100.0 & 100.0 & 100.0 & 100.0 & 100.0 & 100.0 & 99.7 & 99.7 & 99.7 & 16 \\
\hline 17 & 0.0 & 0.2 & 0.2 & 0.2 & 0.2 & 0.2 & 0.2 & 0.2 & 0.2 & 0.2 & 0.2 & 0.2 & 0.0 & 0.0 & 0.0 & 0.0 & & 100.0 & 100.0 & 100.0 & 100.0 & 100.0 & 100.0 & 100.0 & 99.7 & 99.7 & 99.7 & 17 \\
\hline 18 & 0.0 & 0.2 & 0.2 & 0.2 & 0.2 & 0.2 & 0.2 & 0.2 & 0.2 & 0.2 & 0.2 & 0.2 & 0.0 & 0.0 & 0.0 & 0.0 & 0.0 & & 100.0 & 100.0 & 100.0 & 100.0 & 100.0 & 100.0 & 99.7 & 99.7 & 99.7 & 18 \\
\hline 19 & 0.0 & 0.2 & 0.2 & 0.2 & 0.2 & 0.2 & 0.2 & 0.2 & 0.2 & 0.2 & 0.2 & 0.2 & 0.0 & 0.0 & 0.0 & 0.0 & 0.0 & 0.0 & & 100.0 & 100.0 & 100.0 & 100.0 & 100.0 & 99.7 & 99.7 & 99.7 & 19 \\
\hline 20 & 0.0 & 0.2 & 0.2 & 0.2 & 0.2 & 0.2 & 0.2 & 0.2 & 0.2 & 0.2 & 0.2 & 0.2 & 0.0 & 0.0 & 0.0 & 0.0 & 0.0 & 0.0 & 0.0 & & 100.0 & 100.0 & 100.0 & 100.0 & 99.7 & 99.7 & 99.7 & 20 \\
\hline 21 & 0.0 & 0.2 & 0.2 & 0.2 & 0.2 & 0.2 & 0.2 & 0.2 & 0.2 & 0.2 & 0.2 & 0.2 & 0.0 & 0.0 & 0.0 & 0.0 & 0.0 & 0.0 & 0.0 & 0.0 & & 100.0 & 100.0 & 100.0 & 99.7 & 99.7 & 99.7 & 21 \\
\hline 22 & 0.0 & 0.2 & 0.2 & 0.2 & 0.2 & 0.2 & 0.2 & 0.2 & 0.2 & 0.2 & 0.2 & 0.2 & 0.0 & 0.0 & 0.0 & 0.0 & 0.0 & 0.0 & 0.0 & 0.0 & 0.0 & & 100.0 & 100.0 & 99.7 & 99.7 & 99.7 & 22 \\
\hline 23 & 0.0 & 0.2 & 0.2 & 0.2 & 0.2 & 0.2 & 0.2 & 0.2 & 0.2 & 0.2 & 0.2 & 0.2 & 0.0 & 0.0 & 0.0 & 0.0 & 0.0 & 0.0 & 0.0 & 0.0 & 0.0 & 0.0 & & 100.0 & 99.7 & 99.7 & 99.7 & 23 \\
\hline 24 & 0.0 & 0.2 & 0.2 & 0.2 & 0.2 & 0.2 & 0.2 & 0.2 & 0.2 & 0.2 & 0.2 & 0.2 & 0.0 & 0.0 & 0.0 & 0.0 & 0.0 & 0.0 & 0.0 & 0.0 & 0.0 & 0.0 & 0.0 & & 99.7 & 99.7 & 99.7 & 24 \\
\hline 25 & 0.3 & 0.2 & 0.2 & 0.2 & 0.2 & 0.2 & 0.2 & 0.2 & 0.2 & 0.2 & 0.2 & 0.2 & 0.3 & 0.3 & 0.3 & 0.3 & 0.3 & 0.3 & 0.3 & 0.3 & 0.3 & 0.3 & 0.3 & 0.3 & & 99.7 & 99.7 & 25 \\
\hline 26 & 0.3 & 0.2 & 0.2 & 0.2 & 0.2 & 0.2 & 0.2 & 0.2 & 0.2 & 0.2 & 0.2 & 0.2 & 0.3 & 0.3 & 0.3 & 0.3 & 0.3 & 0.3 & 0.3 & 0.3 & 0.3 & 0.3 & 0.3 & 0.3 & 0.3 & & 100.0 & 26 \\
\hline \multirow[t]{2}{*}{27} & 0.3 & 0.2 & 0.2 & 0.2 & 0.2 & 0.2 & 0.2 & 0.2 & 0.2 & 0.2 & 0.2 & 0.2 & 0.3 & 0.3 & 0.3 & 0.3 & 0.3 & 0.3 & 0.3 & 0.3 & 0.3 & 0.3 & 0.3 & 0.3 & 0.3 & 0.0 & & 27 \\
\hline & 1 & 2 & 3 & 4 & 5 & 6 & 7 & 8 & 9 & 10 & 11 & 12 & 13 & 14 & 15 & 16 & 17 & 18 & 19 & 20 & 21 & 22 & 23 & 24 & 25 & 26 & 27 & \\
\hline
\end{tabular}

CP009102.1 S. Typhimurium strain 1331

S. Typhimurium Egy 1

S. Typhimurium Egy 2

CP024619.1 S. Typhimurium BL10

LT795114.1 S. Typhimurium VNB151 CP014979.2 S. Typhimurium CDC H2662 CP019442.1 S. Typhimurium 81741

CP014969.1 S. Typhimurium USDA-ARS-USMA CP014967.1 S. Typhimurium CDC2011K-1702 CP012985.1S. Typhimurium RM9437 CP012681.1S. Typhimurium 33676 AY649718.1 S. Typhimurium SGSC2193 CP021462.1S. Typhimurium UGA14e CP028199.1 S. Typhimurium CFSAN018746 CP026700.1S. Typhimurium AR_0031 LT855376.1 S. Typhimurium STMU2UK CP013720.1 S. Typhimurium RM10607 CP002487.1S. Typhimurium ST4/74 HM920247.1 S. Typhimurium IVRI AP011957.1S. Typhimurium T000240 FQ312003.1 S. Typhimurium SL1344 CP001363.1S. Typhimurium $14028 \mathrm{~S}$ EF599295.1 S. Typhimurium 95 DQ095487.1 S. Typhimurium LT 2 LN999997.1 S. Typhimurium S04698-09| CP007581.1 S. Typhimurium 138736 DQ095491.1S. Typhimurium $\$ 0591703$

Figure 6. Amino acid sequence distance performed using the CLUSTAL W multiple sequence alignment program and version 1.83 of MegAlign module of Lasergene DNAStar software Pairwise for fliC gene among two Egyptian Salmonella strains (S. Typhimurium Egy 1(biphasic) and $S$. Typhimurium Egy 2 (monophasic)).

S._Typhimurium_Egy_1

CP001363.1_S._Typhimurium_14028S EF599295.1_S._Typhimurium_95 FQ312003.1_S._Typhimurium_SL1344 AP011957.1_S._Typhimurium_T000240 HM920247.1_S._Typhimurium_IVRI CP002487.1_S._Typhimurium_ST4/74 CP013720.1_S._Typhimurium_RM10607 LT855376.1_S._Typhimurium_STMU2UK CP026700.1S. Typhimurium AR 0031 CP028199.1_S._Typhimurium_CFSAN018746 CP021462.1_S._Typhimurium_UGA14e CP009102.1_S._Typhimurium_strain_13311 DQ095487.1_S._Typhimurium_LT_2

S. Typhimurium Egy 2 CP024619.1_S._Typhimurium_BL10 LT795114.1_S. Typhimurium_VNB151 CP014979.2_S._Typhimurium_CDC_H2662 CP019442.1_S. Typhimurium 81741 CP014969.1_S._Typhimurium_USDA-ARS-USMARC-1808 CP014967.1_S._Typhimurium_CDC 2011K-1702 CP012985.1_S._Typhimurium_RM9437 AY649718.1_S._Typhimurium_SGSC2193

CP007581.1_S._Typhimurium_138736 DQ095491.1_S._Typhimurium_S05917_03

CP012681.1_S._Typhimurium_33676 LN999997.1_S._Typhimurium_SO4698-09_I

\section{$\stackrel{\vdash}{0.0002}$}

Figure 7. Phylogenetic analysis of Salmonella Typhimurium using fliC gene sequence performed by maximum likelihood, neighbor-joining and maximum parsimony implemented in MEGA6. The amino acid sequence of two Egyptian strain (Mk103394 and Mk103395) were closely related to sequences recorded in GenBank (CP024619 for S. Typhimurium BL10, LT795114 for $S$. Typhimurium VNB151, CP014979 for $S$. Typhimurium CDC H2662, CP019442 for $S$. Typhimurium 81741, CP014969 for S. Typhimurium USDA-ARS-USMA, CP014967 for S. Typhimurium CDC2011K-1702, CP012985 for $S$. Typhimurium, CP012681 for S. Typhimurium 33676RM9437 and AY649718 for $S$. Typhimurium SGSC2193). 


\section{CONCLUSION}

The duplex real-time PCR is a rapid and robust method for detection of genus Salmonella and can be used for identification and differentiation of $S$. Typhimurium and the most common variant $S .1,4$, [5], 12:i:-.

\section{DECLARATIONS}

\section{Acknowledgments}

This study was supported by the research group of Animal Health Research Institute, Egypt

\section{Competing interests}

The authors have declared that no competing interest exists.

\section{Authors' contribution}

All authors contributed equally to this work

\section{REFERENCES}

Abd El-Lattief A (2014). Detection of multidrug resistant Salmonellae. master thesis, Microbiology department, Faculty of veterinary medicine, Cairo University.

Anon (2010). Scientific opinion on monitoring and assessment of the public health risk of Salmonella Typhimurium-like strains. EFSA Journal, 8 (10):1826. DOI: https:// doi.org/ 10. 290 3/ j.e fsa. 2010.1826 .

Bugarel M, Granier SA, Bonin E, Vignaud ML, Roussel S, and Fach P (2012). Genetic diversity in monophasic $(1,4,[5], 12: \mathrm{i}:-$ and $1,4,[5], 12:-: 1,2)$ and in non-motile $(1,4,[5], 12:-:-)$ variants of Salmonella enterica Typhimurium. Food Research International, $45 \quad(10): \quad 16-1024 . \quad$ DOI: https://doi.org/10.1016/j.foodres.2011.06.057

Burnens AP, Stanley J, Sack R, Hunziker P, Brodard I and Nicolet J (1997). The flagellin $\mathrm{N}$ methylase gene $f l i B$ and an adjacent serovar-specific IS200 element in Salmonella Typhimurium. Microbiology, 143:1539-1547. DOI:https:/ /doi.org/ 10.1099/ 0 0221287-143-5-1539

De Vries N, Zwaagstra KA, Huis JHJ, Veld INT, Van Knapen F, VanZijderveld FG and Kusters JG (1998). Production of monoclonal antibodies specific for the $\mathrm{i}$ and 1, 2 flagellar antigens of Salmonella Typhimurium and characterization of their respective epitopes. Journal of Applied and Environmental Microbiology, 64(12) :5033-5038. Avaliable at :https://www.ncbi.nlm.nih.gov/pmc/articles/PMC90964/

Dhanani AS, Block G, Forgetta V, Topp E, Beiko R and Diarra M (2015). Genomic comparison of non-typhoidal Salmonella enterica serovars Typhimurium, Enteritidis, Heidelberg, Hadar and Kentucky isolates from broiler chickens. PLOS One, 10(9): 0137697e. DOI:https: //doi.org/10. 1371 / journal.pone.0137697

European Food Safety Authority (EFSA) (2010). Scientific opinion on monitoring and assessment of the public health risk of "Salmonella Typhimurium-like" strains. EFSA Journal, 8: 1826. DOI: https://doi.org/10.2903/j.efsa.2010.1826

Foley SL, Lynne AM and Nayak R (2008). Salmonella challenges: Prevalence in swine and poultry and potential pathogenicity of such isolates. Journal of Animals Science, 86:149-162. DOI: https://doi.org/ 10.2527/jas.2007-0464
Grimont PAD and Weill FX (2007). Antigenic Formulas of the Salmonella Serovars, $9^{\text {th }}$ edition. WHO Collaborating Centre for Reference and Research on Salmonella. Institute Pasteur, Paris.

Hopkins KL, Kirchner M, Guerra B, Granier SA, Lucarelli C and Porrero MC (2010). Multi resistant Salmonella enterica serovar 4, [5], 12:i:- in Europe: a new pandemic strain. Eurosurveillance Journal, 15: 19580. DOI: https: //doi.o rg/10. 2807 /ese. 15. 22.19580-en

Hua Zou Q, Qing Li R, Rong Liu G and Lin Liu S (2016). Genotyping of Salmonella with lineage-specific genes: correlation with serotyping International, Journal of Infectious Diseases, 49:134140. DOI:https://doi.org/10.1016/j.ijid.2016.05.029.

Ido N, Lee KI, Iwabuchi K, Izumiya H and Uchida I (2014). Characteristics of Salmonella enterica Serovar 4, [5], 12:i:- as a Monophasic Variant of Serovar Typhimurium. PLoS ONE, 9(8): e104380. DOI: https:/ /doi.org /10.1371 /journal .pone.0104380.

Imre A, Olasz F and Nagy B (2005). Development of a PCR system for the characterisation of Salmonella flagellin genes. Acta Veterinaria Hungarica, 53:163-172. https://doi.org/10.1556/AVet.53.2005.2.2.

ISO/TR6579 -3 (2014). Microbiology of food chain horizontal method for the detection, enumeration and serotyping of Salmonella -part3 guidelines for serotyping of Salmonella spp. ed 1, p:33. Avaliable at: https ://www.iso.org/standard/56714.html.

Joys TM (1985). The covalent structure of the phase-1 flagellar filament protein of Salmonella Typhimurium and its comparison with other flagellins. The Journal of Biological Chemistry, 260:15758-15761. Available at: https:// www. Jbc .org / content/260/29/15758.

Kim S, Frye JG, Hu J, Paula J, Cray F, Gautom R, and Boyle SD (2006). Multiplex PCR-based method for identification of common clinical serotypes of Salmonella enterica subsp. enterica. Journal of Clinical Microbiology, 44(10): 3608-3615. DOI:https://doi.org 10. 1128 /JCM .00701-06.

Malorny B, Made D, Teufel P, Berghof-Jager C, Huber I, Anderson A and Helmuth R (2007). Multicenter validation study of two block cycler- and one capillary-based real-time PCR methods for the detection of Salmonella in milk powder. International Journal of Food Microbiology, 117 (2): 211-218. DOI: https://doi.org /10.1016 /j.ijfoodmicro.2007.04.004

O'Regan E, McCabe E, Burgess C, McGuinness S, Barry T, Duffy G, Whyte P and Fanning S (2008) .Development of a real-time multiplex PCR assay for the detection of multiple Salmonella serotypes in chicken samples . BMC Microbiology, 8: 156167.DOI: https://doi.org/10.1186/1471-2180-8-156.

Osman KM, Marouf SH, Erfan AM and Alatfeehy N (2014a). Salmonella enterica in imported and domestic day-old turkey poults in Egypt:Repertoire of virulence genes and their antimicrobial resistance profiles .OIE Revue Scientifiqueet Technique, 33(3):1017-1026. DOI: https://doi.org/10.20506/rst.33.3.2338.

Osman KM, Marouf SH, Zolnikov TR, and Alatfeehy N (2014b). Isolation and characterization of Salmonella enterica in day-old ducklings in Egypt. Pathogens and Global Health, 108(1):37-48. DOI: https://doi.org/10.1179/2047773213Y.0000000118.

Pathmanathan SG, Cardona-Castro N, Sanchez-Jimenez MM, CorreaOchoa MM, Puthucheary SD and Thong KL (2003). Simple and rapid detection of Salmonella strains by direct PCR amplification of the hilA gene. Journal of Medical Microbiology, 52(9): 773-776. DOI: https ://doi.org. 10. 1099 /jmm .0.05188-0.

Pereira F, Carneiro J, Matthiesen R, van Asch B, Pinto N, Gusmão L and Amorim A (2010). Identification of species by multiplex analysis of variable-length sequences. Nucleic Acids Research, 38 (22): 203. DOI:https:// doi. org/10.1093 /nar/ gkq865. PM ID 20923781.

Persad AK and LeJeune J (2018). A Review of Current Research and Knowledge Gaps in the Epidemiology of Shiga ToxinProducing Escherichia coli and Salmonella spp. in Trinidad and 
Tobago. Veterinary Sciences, 5(2): 42. DOI:https://doi.org /10.3390/vetsci5020042.

Prendergast DM, Hand D, NíGhallchóir E, McCabe, E, Fanning S, Griffin M, Egan J and Gutierrez M (2013). A multiplex real-time PCR assay for the identification and differentiation of Salmonella enterica serovar Typhimurium and monophasic serovar 4,[5],12:i:-. International Journal of Food Microbiology, 166(1): 48-53.DOI: https://doi.org/ 10.1016 /j.ijfoodmicro. 2013.0 5.031

Sandjong BT, Sessitsch A , Liebana E , Kornschober C, Allerberger F, Hachler H and Bodrossy L (2007). Salmonella enterica subsp. enterica serovar Typhimurium strain S05917 03 phase 1 flagellin (fliC) gene, partial cds. Journal of Microbiological Methods, 69(1): 23-36. Available at: https:// www.ncbi.nlm.nih.gov/gene? $\mathrm{Db}=$ gene $\& \mathrm{Cmd}=$ Detail sSearch\&T erm= 1253480 .

Shaw JA, Henard CA, Liu L, Dieckman LM, Andrés VázquezTorres AV and Bourret TJ (2018). Salmonella enterica serovar Typhimurium has three transketolase enzymes contributing to the pentose phosphate pathway.Journal of biological Chemistry, 293(29): 11271-11282. DOI: https:// doi.org 10.1074/jbc.RA 118.003661 .

Shin HH, Hwang BH and Cha HJ (2016). Multiplex 16S rRNA-derived geno-biochip for detection of 16 bacterial pathogens from contaminated foods. Biotechnol Journal, 11(11): 1405-1414. DOI: https://doi.org/ 10.1002/biot.201600043.

Silverman M, Zieg J and Hilmen M (1979). Phase variation in Salmonella :Genetic analysis of a recombinational switch . ResearchGate, 76(1): 391-5. DOI: https:// doi .org /10.1073/pnas .76.1.391.

Soumet C, Ermel G, Rose V, Drouin P, Salvat G and Colin P (1999). Identification by a multiplex PCR based assay of Salmonella Typhimurium and Salmonella Enteritidis strains from environmental swabs of poultry houses. Letters in Applied Microbiology, 29:1-6. DOI: https://doi.org/10.1046/ j.1365-26 72.1 9 99.00559.x.
Soyer Y, Moreno SA, Davis MA, Maurer J, McDonough PL, Schoonmaker-Bopp DJ, Dumas NB, Root T, Warnick LD, Gröhn YT and Wiedmann M (2009). Salmonella enterica serotype 4,5,12:i:-, an emerging Salmonella serotype that represents multiple distinct clones. Journal of Clinical Microbiology, 47: 3546-3556. DOI: https://doi.org /10.1128/JCM.00546-09

Tamura K, Stecher G, Peterson D, Filipski A and Kumar S (2013). MEGA6: molecular evolutionary genetics analysis version 6.0. Molecular Biology journal, 30: 2725-2729. DOI: https://www.doi.org 10.1093/molbev/mst197

Tennant SM, Diallo S, Levy H, Livio S, Sow SO, Tapia M, Fields PI, Mikoleit M, Tamboura B, Kotloff KL, Nataro JP, Galen JE and Levine MM (2010). Identification by PCR of non-typhoidal Salmonella enterica serovars associated with invasive infections among febrile patients in Mali. PLoS Neglected Tropical Disease, 4(3): e621. DOI: https://doi.org/ 10.1371/journal.pntd.0000621.

Thompson JD, Higgins DG and Gibson TJ (1994). CLUSTAL W: improving the sensitivity of progressive multiple sequence alignment through sequence weighting, position-specific gap penalties and weight matrix choice . Nucleic Acids Research, 22(22): $\quad 4673-\quad 4680 . \quad 40$ https://www.doi.org/10.1093/nar/22.22.4673

Woo PCY, Kenneth HLN, Susanna KPL, Kam-tong Yip, Ami MYF, Kitwah L, Dorothy MWT, Tak-lun Q, and Kwok-yung Y (2003). Usefulness of the MicroSeq $50016 \mathrm{~S}$ ribosomal DNA-based identification system for identification of clinically significant bacterial isolates with ambiguous biochemical profiles. Journal of Clinical Microbiology, 41: 1996-2001. DOI :https://doi.org / 10.1128/JCM.41.5.1996-2001.2003.

Yang X, Brisbin J, Yu H, Wang Q, Yin F, Zhang Y, Sabour P, Sharif S and Gong J (2014). Selected Lactic Acid-Producing Bacterial Isolates with the Capacity to Reduce Salmonella Translocation and Virulence Gene Expression in Chickens. PLOS ONE, 9(4): 93022. DOI: https://doi.org/10.1371/journal.pone.0093022 